\title{
ANALISIS PERSEPSI DAN EKSPEKTASI MAHASISWA TERHADAP PERAN DAN FUNGSI DOSEN PEMBIMBING AKADEMIK
}

\author{
Intan Kumalasari 1 \\ ${ }^{1}$ Prodi D3 Keperawatan Lubuklinggau, Poltekkes Kemenkes Palembang
}

Email : zoominar123@gmail.com

\begin{abstract}
Academic supervisors are the most appropriate resource for students to complete their education process. Supervisors can also act as motivators, consultants and collaborators. This study aims to analyze students' perceptions and expectations of the role and function of academic advisors at the Poltekkes Palembang by emphasizing the dimensions of tangible, reliability, responsiveness, assurance and empathy. This study used the Importance-Performance Analysis (IPA) method and mapped into a Cartesian diagram. Measuring the overall level of student satisfaction was using the Customer Satisfaction Index (CSI). The sample of this research was 228 Poltekkes Palembang students who were selected using proportional stratified random sampling technique. Data collection was using a questionnaire sheet with a Likert scale and analyzed using analysis of the level of interest and customer satisfaction. The statistical test showed that the attribute that has the most satisfactory performance was the appearance of the academic supervisor with a mean of 3.28, while the attributes that need to be prioritized for improvement were special attention to individual students with a mean of 2.42 . Through the calculation of CSI, the value was 73.7\% (0.66-0.80). This shows that the index of student satisfaction with the role and function of academic advisers was in satisfactory criteria. The performance of lecturers as academic advisers must be improved and become a lecturer 's attention, especially in several attributes, namely the closeness of the relationship, attention to student difficulties, providing information, and monitoring student academic development.
\end{abstract}

Keywords: academic supervisor, perception, student expectation.

\begin{abstract}
Abstrak
Dosen pembimbing akademik merupakan narasumber yang paling tepat bagi mahasiswa untuk menyelesaikan proses pendidikannya. Dosen pembimbing juga dapat berperan sebagai motivator, konsultan dan kolaborator. Penelitian ini bertujuan untuk menganalisis persepsi dan ekspektasi mahasiswa terhadap peran dan fungsi dosen pembimbing akademik di Poltekkes Palembang dengan menekankan pada dimensi tangible, reliability, responsiveness, assurance dan emphaty. Penelitian ini menggunakan metode Importance-Performance Analysis (IPA) dan dipetakan kedalam diagram kartesius. Pengukuran tingkat kepuasan mahasiswa secara keseluruhan menggunakan Customer Satisfaction Index (CSI). Sampel penelitian ini adalah mahasiswa Poltekkes Palembang berjumlah 228 orang yang diseleksi dengan menggunakan teknik proportionale stratified random sampling. Pengumpulan data menggunakan lembar kuesioner dengan skala likert dan dianalisis menggunakan analisis tingkat kepentingan dan kepuasan pelanggan. Uji statistik menunjukkan atribut yang memiliki kinerja paling memuaskan adalah penampilan pembimbing akademik dengan rerata 3,28, sedangkan atributatribut yang perlu diprioritaskan untuk diperbaiki adalah perhatian khusus kepada mahasiswa secara individual dengan rerata sebesar 2,42. Melalui perhitungan CSI diperoleh nilai sebesar 73,7\% (0,66-0,80). Hal ini menunjukkan bahwa indeks kepuasan mahasiswa terhadap peran dan fungsi pembimbing akademik berada pada kriteria memuaskan. Kinerja dosen sebagai pembimbing akademik harus ditingkatkan dan menjadi perhatian dosen terutama pada beberapa atribut yaitu kedekatan hubungan, perhatian terhadap kesulitan mahasiswa, sebagai pemberi informasi, dan memantau perkembangan akademik mahasiswa.
\end{abstract}

Kata kunci: dosen pembimbing akademik, persepsi, ekspektasi mahasiswa. 


\section{Pendahuluan}

Pendidikan Tinggi (PT) adalah jenjang pendidikan setelah pendidikan menengah yang mencakup program diploma, program sarjana, program magister, program doktor, program profesi, serta program spesialis. Perguruan Tinggi menyelenggarakan Pendidikan berdasarkan kebudayaan bangsa Indonesia (PP No. 4 tahun 2014). Salah satu faktor yang mempunya andil sangat besar dalam keberlangsungan proses pendidikan adalah dosen. Dosen adalah salah satu komponen esensial dalam suatu sistem pendidikan di perguruan tinggi. Peran, tugas dan tanggung jawab dosen sangat penting dalam mewujudkan tujuan pendidikan nasional yaitu mencerdaskan kehidupan bangsa dan meningkatkan kualitas manusia Indonesia. Untuk melaksanakan fungsi, peran, dan kedudukan yang sangat strategis tersebut, diperlukan dosen yang profesional (Dikti, 2010). Dosen adalah pendidik profesional dan ilmuwan dengan tugas utama mentransformasikan, mengembangkan, dan menyebarluaskan ilmu pengetahuan dan teknologi melalui pendidikan, penelitian, dan pengabdian kepada masyarakat.

Perguruan tinggi memikul tanggung jawab dalam pembinaan mahasiswa untuk mencapai kesuksesan yakni dengan cara mendorong mahasiswa untuk melakukan kegiatan studi secara optimal, baik dalam perkuliahan dan kehidupan mahasiswa selama menjalani studi (Silitonga, 2008). Kenyataan menunjukkan belum banyak mahasiswa yang terbuka pada dirinya sendiri, mahasiswa sukar mengambil kebijakan yang tepat untuk dirinya terutama yang berhubungan dengan studinya. Kondisi tersebut mengisyaratkan bahwa bantuan pelayanan kepada mahasiswa sangat diperlukan dengan cara mengefektifkan bimbingan akademik melalui dosen pembimbing akademik (Ginting, 2003).

Mutu pendidikan khususnya tingkat prestasi belajar selalu menjadi bahan pembicaraan dari berbagai kalangan, baik birokrat, pemerhati, pengelola perguruan tinggi maupun dari kalangan dosen. Salah satu peran seorang dosen adalah sebagai pembimbing akademik. Para ahli psikologi menyadari pentingnya bimbingan akademis dari para dosen dalam rangka peningkatan prestasi belajar mahasiswa agar kualitas pendidikan khususnya di Perguruan Tinggi dapat diperoleh secara optimal.

Namun, berdasarkan beberapa hasil penelitian terdahulu diketahui bahwa banyak diantara para dosen selaku pembimbing akademis belum melakukan perannya secara ideal. Pada umumnya mereka hanya memberikan pengesahan Kartu Rencana Studi (KRS), mengevaluasi boleh atau tidaknya mengikuti ujian atas dasar kehadiran kuliah, mengesahkan berapa jumlah Satuan Kredit Semester (SKS) yang boleh diambil dan mata kuliah mana yang boleh diambil atas dasar Indeks Prestasi (IP) yang dicapai sebelumnya, atau sekedar mengesahkan berapa jumlah SKS yang telah dicapai guna persyaratan akademis tertentu, mengesahkan berapa IP dan IPK yang telah dicapai mahasiswa selama mengikuti kuliah guna mendapatkan transkrip akademik.

Dosen dihadapkan pada tuntutan yang semakin besar atas peran dan fungsinya sebagai pembimbing akademik, apalagi dengan adanya perkembangan model pembelajaran saat ini yang telah maju pesat. Adanya perubahan dari model yang memfokuskan pada teacher centered learning beralih ke arah student centered learning. Sistem pembelajaran student centered membutuhkan perubahan paradigma para pelaku pembelajaran baik dosen maupun mahasiswa. Dosen berperan sebagai fasilitator dan motivator, sedangkan mahasiswa berperan sebagai pelaku pembelajar aktif dan mandiri. Kedudukan dosen bukan sebagai satusatunya sumber materi pembelajaran tapi sebagai salah satu sumber materi pembelajaran dan kedudukan mahasiswa sebagai pengguna materi pembelajaran.

Dosen pembimbing akademik adalah staf pengajar tetap suatu perguruan tinggi yang paling tepat untuk menjadi sumber bantuan nasehat akademik, agar para mahasiswa dapat menyelesaikan tugasnya sebagai mahasiswa. Bantuan yang diberikan oleh para dosen penasehat akademik kepada individu-individu mahasiswa dimaksudkan agar mahasiswa dapat mengembangkan pandangan, mengambil keputusan dan bertanggung jawab terhadap dirinya sendiri (Sulaiman, 2008). Dosen Pembimbing Akademik turut menentukan prestasi belajar mahasiswa, sehingga dosen diharapkan mampu diharapkan mampu untuk memberikan layanan bantuan kepada mahasiswa bimbingannya dalam upaya keberhasilan studinya.

Persepsi mahasiswa terhadap layanan dosen Pembimbing Akademik dapat diartikan sebagai tingkat Kepuasan atau perasaan yang muncul karena terpenuhinya keinginan atau sebuah harapan. Kepuasan mahasiswa adalah sikap positif mahasiswa terhadap pelayanan dosen Pembmbing akademik karena adanya kesesuaian antara harapan dari pelayanan dibandingkan dengan kenyataan yang diterimanya (Sopiatin, 2010). Setidaknya ada beberapa unsur layanan yang menjadi penilaian dan harapan mahasiswa agar dapat dipenuhi oleh dosen pembimbingan akademik yaitu dimensi fisik, respon ketanggapan, jaminan pelayanan dan empaty dosen Pembimbing Akademik.

Survey pendahuluan yang dilakukan melalui wawancara terhadap 10 orang mahasiswa secara acak, menunjukkan bahwa mahasiswa menemui dosen pembimbing akademik pada awal semester untuk penandatanganan KRS, pada saat menjelang UTS dan UAS dan diakhir semester guna penandatanganan KHS. Mahasiswa belum memanfaatkan secara optimal kehadiran dosen pembimbing akademik diluar urusan akademik dengan alasan sungkan, malu dan sulit mencari waktu yang tepat. Data lain memberikan gambaran bahwa survey kepuasan mahasiswa Poltekkes Palembang tahun 2015 menyimpulkan secara umum, rata-rata 20\% mahasiswa merasa tidak puas terhadap layanan akademik. Padahal sebenarnya Poltekkes Palembang telah menerbitkan buku bimbingan akademik mahasiswa yang menuangkan tugas dan kewajiban pembimbing akademik.

Fenomena yang terjadi di Poltekkes Palembang dan beberapa fakta yang dipaparkan di atas mendorong peneliti untuk melakukan kajian terhadap pelaksanaan bimbingan akademik dengan meneliti "Analisis persepsi dan ekspektasi mahasiswa terhadap peran dan fungsi dosen pembimbing akademik di Poltekkes Palembang”.

\section{Metode Penelitian}

Penelitian ini dilakukan pada bulan Juli sampai dengan September 2016, menggunakan metode ImportancePerformance Analysis (IPA) dan dipetakan kedalam 
diagram kartesius. Pengukuran tingkat kepuasan mahasiswa secara keseluruhan menggunakan Customer Satisfaction Index (CSI). Variabel dalam penelitian ini adalah persepsi dan ekspektasi mahasiswa terhadap proses bimbingan akademik dengan memperhatikan dimensi tangible, reliability, responsiveness, assurance dan emphaty. Populasi penelitian ini adalah mahasiswa semester III dan V Poltekkes Palembang berjumlah 790 orang. Pengambilan sampel menggunakan teknik proportionale stratified random sampling, menggunakan rumus Slovin pada taraf kesalahan 5\%, dengan jumlah sampel 228 orang setelah ditambah $10 \%$ untuk mencegah drop-out. Alat ukur berupa kuesioner sebanyak 19 butir pertanyaan dengan menggunakan skala likert.

\section{Hasil Penelitian}

\section{Karakteristik Responden}

Responden penelitian adalah mahasiswa semester III dan V yang berasal dari 6 Program Studi (Prodi) di lingkungan Poltekkes Palembang yaitu Prodi D3 Keperawatan, Prodi D3 Kebidanan, Prodi D3 Gizi, Prodi D3 Analis Kesehatan, Prodi D3 Farmasi dan Prodi D3 Keperawatan Gigi. Sebagian besar responden yaitu $202(88,6 \%)$ berjenis kelamin perempuan dan $176(73,2 \%)$ tinggal bersama orang tua.

\section{Penilaian Persepsi dan Ekspektasi Mahasiswa Terhadap Peran dan Fungsi Dosen Pembimbing Akademik}

Tabel 1.1. Penilaian Persepsi dan Ekspektasi Mahasiswa

\begin{tabular}{clcc}
\hline No & \multicolumn{1}{c}{ Atribut } & $\begin{array}{c}\text { Rerata } \\
\text { persepsi }\end{array}$ & $\begin{array}{c}\text { Rerata } \\
\text { ekspekt } \\
\text { asi }\end{array}$ \\
\hline \multicolumn{2}{c}{ Dimensi fisik (Tangible) } & & \\
1 & $\begin{array}{l}\text { Penampilan personal } \\
2\end{array}$ & 3,28 & 3,5 \\
& $\begin{array}{l}\text { Sarana tempat layanan } \\
\text { PA }\end{array}$ & 2,78 & 3,52 \\
3 & Ketersediaan buku & 2,98 & 3,43 \\
& catatan PA & & \\
4 & Keramahan PA & 3,27 & 3,78 \\
5 & $\begin{array}{l}\text { Media mencari bantuan } \\
\text { menyelesaikan masalah }\end{array}$ & 3,06 & 3,82 \\
6 & $\begin{array}{l}\text { Terjalin kedekatan } \\
\text { hubungan }\end{array}$ & 2,83 & 3,64 \\
& & &
\end{tabular}

\section{Dimensi ketanggapan (responsiveness)}

7 waktu layanan PA sesuai $\quad 2,66$ kebutuhan mahasiswa

8 dipercaya menjaga $3,17 \quad 3,76$ rahasia

9 mampu memecahkan masalah

10 sarana dalam memperoleh segala informasi pendidikan

\begin{tabular}{|c|c|c|c|}
\hline \multicolumn{4}{|c|}{ Dimensi jaminan mutu (assurence) } \\
\hline 11 & $\begin{array}{l}\text { Sikap pembimbing } \\
\text { akademik }\end{array}$ & 3 & 3,6 \\
\hline 12 & Nyaman saat berdiskusi & 3,01 & 3,67 \\
\hline 13 & Selalu bersikap ramah & 3,21 & 3,71 \\
\hline 14 & $\begin{array}{l}\text { Memiliki pengetahuan } \\
\text { yang luas }\end{array}$ & 3,25 & 3,81 \\
\hline \multicolumn{4}{|c|}{ Dimensi empati (emphaty) } \\
\hline 15 & $\begin{array}{l}\text { layanan rutin dan } \\
\text { berkelanjutan }\end{array}$ & 2,55 & 3,55 \\
\hline 16 & $\begin{array}{l}\text { Memberikan perhatian } \\
\text { khusus }\end{array}$ & 2,42 & 3,34 \\
\hline 17 & $\begin{array}{l}\text { Selalu menanyakan } \\
\text { kendala/masalah yang } \\
\text { dialami mahasiswa }\end{array}$ & 2,9 & 3,64 \\
\hline 18 & $\begin{array}{l}\text { Memantau } \\
\text { perkembangan akademik } \\
\text { mahasiswa }\end{array}$ & 2,9 & 3,69 \\
\hline 19 & $\begin{array}{l}\text { Inisiatif tinggi dalam } \\
\text { memberikan layanan }\end{array}$ & 2,68 & 3,46 \\
\hline
\end{tabular}

Tabel 1.1 menunjukkan bahwa atribut yang dianggap memiliki kinerja paling memuaskan adalah penampilan personal pembimbing akademik dengan nilai rerata persepsi sebesar 3,28. Hasil ini menunjukkan bahwa secara umum pembimbing akademik telah berpenampilan rapih dalam kesehariannya. Sementara untuk atribut layanan yang dianggap penting untuk dipenuhi dosen pembimbing akademik namun secara kinerja belum optimal adalah peran pembimbing akademik sebagai media dalam memberikan bantuan penyelesaian masalah mahasiswa dengan nilai rerata ekspektasi sebesar 3,82.

\section{Indeks Kepuasan Pengguna (Customer satisfaction index (CSI)}

Tabel 1.2. Indeks Kepuasan Mahasiswa

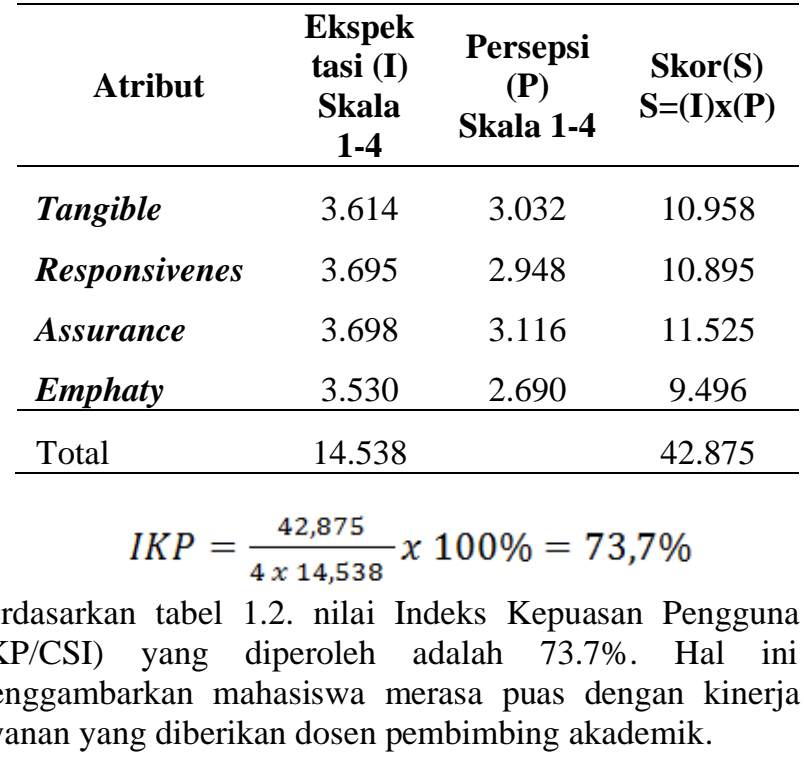




\section{Importance Performance Analysis (IPA)}

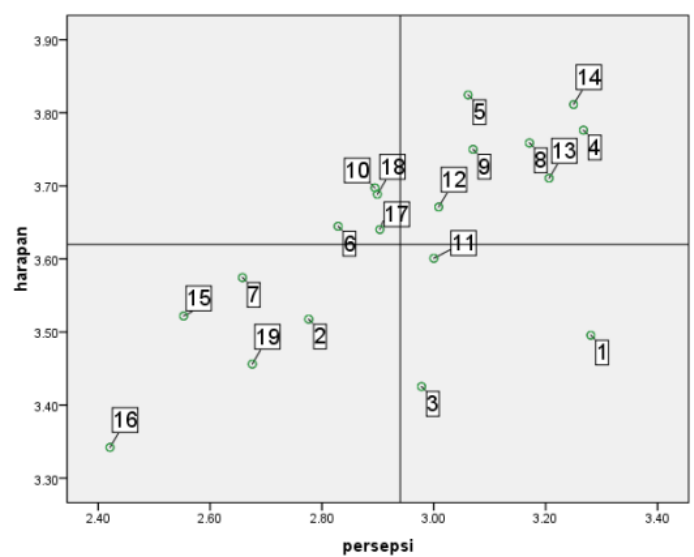

Gambar 1. Diagram kartesius ImportancePerformance Analysis

Hasil Importance Performance Analysis (IPA) yaitu pengukuran tingkat kesesuaian antara kinerja yang telah diberikan dosen pembimbing akademik dengan kepuasan yang dirasakan mahasiswa sebagai penerima layanan dijabarkan kedalam diagram kartesius pada gambar 1 dimana sumbu X merupakan nilai rerata tingkat persepsi mahasiswa terhadap kinerja dosen pembimbing akademik dan sumbu Y merupakan nilai rerata ekspektasi/harapan mahasiswa terhadap kinerja dosen pembimbing akademik (F. Tjiptono, dan G. Chandra, 2005). Adapun atribut yang masuk kuadaran I dianggap mahasiswa memiliki tingkat ekspektasi atau harapan yang tinggi, tetapi dinilai memiliki kinerja yang relatif rendah. Atribut tersebut diantaranya adalah kedekatan hubungan pembimbing akademik mahasiswa (6), layanan bimbingan akademik dijadikan sebagai sarana bagi mahasiswa dalam peroleh segala informasi terkait pendidikan (10), pembimbing akademik selalu menanyakan mahasiswa mengenai kemungkinan adanya kesulitan belajar atau masalah lain (17) dan pembimbing akademik memantau perkembangan akademik mahasiswa (18). Ke-4 atribut yang masuk kedalam kuadran 1 ini merupakan prioritas utama yang harus segera ditingkatkan kinerjanya.

Sementara atribut yang terdapat pada kuadran II adalah atribut yang perlu dipertahankan kinerjanya oleh dosen pembimbing akademik, karena merupakan suatu keunggulan dan dianggap telah memenuhi ekspektasi atau harapan mahasiswa dari dosen pembimbing akademik. Adapun atribut yang dimaksud adalah : Keramahan pembimbing akademik (4), Bimbingan akademik dijadikan sarana bagi mahasiswa untuk cari bantuan selesaikan masalah (5), Pembimbing akademik dapat dipercaya menjaga rahasia (8), Pembimbing akademik dapat dipercaya mampu bantu pecahkan masalah (9) dan Mahasiswa merasa nyaman saat berdiskusi dengan pembimbing akademik (12), Pembimbing akademik secara konsisten bersikap ramah terhadap mahasiswa (13) dan Pembimbing akademik memiliki pengetahuan yang luas untuk menjawab pertanyaan atas permasalahan mahasiswa (14).

\section{Pembahasan}

Hasil penilaian persepsional mahasiswa terhadap atribut yang dianggap memiliki kinerja paling memuaskan dari dosen pembimbing akademik adalah penampilan personal dosen pembimbing akademik yaitu dengan nilai rata-rata sebesar 3,28. Hasil ini menunjukkan bahwa secara umum pembimbing akademik telah berpenampilan rapih dalam kesehariannya. Kepribadian seorang dosen sangat mempengaruhi minat belajar bagi para mahasiswanya.

Sumber daya manusia di perguruan tinggi yang profesional khususnya dosen memiliki peran yang sangat penting untuk memotivasi mahasiswa dalam perkuliahan. Penampilan seorang dosen dapat menimbulkan rasa percaya diri yang simpatik terhadap mahasiswa, sehingga tidak mengherankan penampilan dosen dalam memberikan perkuliahan perlu diperhatikan karena sangat mempengaruhi motivasi belajar mahasiswa. Namun disisi lain, seorang dosen pembimbing akademik juga harus memperhatikan tingkat kinerjanya yang masih rendah. Hal ini berarti kualitas jasa yang diberikan dosen kepada mahasiswa masih dianggap kurang optimal dan perlu peningkatan. Adapun atribut yang dipersepsikan mahasiswa masih rendah dengan nilai rerata 2,42 tapi memiliki ekspektasi yang cukup tinggi yaitu 3,34 adalah fakta yang menyatakan bahwa pembimbing akademik belum memberikan perhatian khusus pada mahasiswa secara individual. Hasil ini menunjukkan adanya gap atau kesenjangan yang cukup besar yaitu 0,92 antara nilai pelayanan yang diterima mahasiswa dengan ekspektasi mahasiswa itu sendiri. Kesenjangan yang muncul ini akan memberikan dampak yang signifikan atas kepuasan mahasiswa itu sendiri. Hasil ini juga menunjukkan masih kurang maksimalnya kinerja dosen pembimbing akademik dalam peran dan fungsinya sebagai dosen pembimbing akademik.

Seorang dosen pembimbing akademik tidak hanya bertanggung jawab dengan nilai akademik mahasiswa bimbingannya, tidak hanya terfokus dengan masalah seputar akademik atau di dalam kehidupan kampus saja, tetapi juga masalah-masalah non akademik. Seorang dosen harus hadir sebagai sosok orang tua yang mengayomi, saudara yang nyaman diajak berdiskusi dan juga sebagai teman yang dapat diajak berkeluh kesah. Seorang dosen pembimbing akademik harus mampu mengembangkan kepribadian mahasiswa agar lebih terarah, memantau mahasiswa menyesuaikan dengan kehidupan kampus (Mulyadi, 2013) dan mampu melejitkan potensi yang ada pada mahasiswa dan menjadikannya prestasi.

Hasil penilaian ekspektasi atau harapan dari atribut layanan yang dianggap mahasiswa paling penting dipenuhi oleh seorang dosen pembimbing akademik adalah bimbingan akademik dapat dijadikan sarana bagi mahasiswa untuk mencari bantuan dalam menyelesaikan masalah yang dihadapinya, yaitu dengan rata-rata nilai harapan sebesar 3,82 . Hal tersebut dikarenakan mahasiswa berharap bahwa pembimbing akademik mampu memberikan solusi dari setiap permasalah yang dihadapi oleh mahasiswanya, sehingga sangat diperlukan wawasan pengetahuan yang luas bagi pembimbing akademik untuk menjawab pertanyaan atas permasalahan yang dihadapi mahasiswa.

Hasil perhitungan indeks kepuasan mahasiswa terhadap dosen pembimbing akademik diperoleh nilai 
sebesar 73,7\%. Hal ini menggambarkan mahasiswa Poltekkes Palembang puas atas kinerja layanan yang diberikan dosen pembimbing akademik. Namun, bila melihat hasil pengukuran importance performance analysis (IPA) beberapa atribut yang masuk kuadran I harus menjadi prioritas utama yang harus segera ditingkatkan kinerjanya. Karena atribut yang ada pada kuadran ini dianggap mahasiswa memiliki tingkat ekspektasi atau harapan yang tinggi, tetapi kenyataannya belum sesuai dengan harapan mahasiswa. Atribut tersebut diantara adalah kedekatan hubungan pembimbing akademik mahasiswa (6), layanan bimbingan akademik yang dijadikan sebagai sarana bagi mahasiswa dalam memperoleh segala informasi terkait pendidikan (10), pembimbing akademik selalu menanyakan mahasiswa mengenai kemungkinan adanya kesulitan belajar atau masalah lain (17) dan pembimbing akademik memantau perkembangan akademik mahasiswa (18).

Kedekatan seorang dosen bimbingan akademik dengan mahasiswa merupakan langkah awal membina hubungan saling percaya (Walgito, 2004). Hal ini terjadi sesuai dengan proses perkembangannya, mahasiswa umumnya berada pada masa peralihan yaitu dari akhir usia remaja menuju awal usia dewasa. Akan terjadi perubahan yang sangat cepat baik dari aspek biologi, intelektual, emosional, sikap menuju kearah kematangan dan kemantapan pribadi Mulyadi (2013). Pada tahap menuju proses pendewasaan ini, tidak semua mahasiswa berhasil melewatinya dengan baik. Ada yang mampu beradaptasi dengan cepat tapi adapula yang lambat, kesulitan beradaptasi dengan lingkungan kampus, kesulitan mencari teman, kesulitan dengan metode belajar yang baru, ditambah konflik internal mahasiswa seperti masalah dengan keluarga, pacar ataupun masalah ekonomi yang bisa menjadi pemicu mahasiswa sulit berkonsentrasi dalam meraih prestasi akademik dan menarik diri dari lingkungan sosial.

Slameto (2005) menunjukkan kehadiran dosen pembimbing akademik sebagai fasilitator, teladan, pemandu, motivator dan konselor sangat diperlukan sekali pada kondisi untuk menumbuhkan rasa percaya diri mahasiswa/I yang dibimbingnya (Prayitno, Amti, 2008). Minat, bakat dan semangat para mahasiswa untuk kembali meraih prestasi akademik maupun non akademik. Ekspektasi yang tinggi dari mahasiswa akan keberadaan dosen pembimbing akademik tentunya menjadi motivasi bagi dosen maupun pengelola akademik untuk melakukan perbaikan dan meningkatkan kinerja layanan yang belum memuaskan mahasiswa di masa yang akan datang.

\section{Kesimpulan}

Tingkat kepuasan mahasiswa terhadap layanan dosen pembimbing akademik di Lingkungan Poltekkes Palembang sudah memuaskan. Terdapat empat atribut yang dianggap penting dalam menentukan tingkat kepuasan mahasiswa yang harus segera menjadi prioritas utama untuk ditingkatkan dosen pembimbing akademik yaitu : (1) kedekatan hubungan pembimbing akademik dengan mahasiswa, (2) layanan bimbingan akademik dijadikan sebagai sarana bagi mahasiswa dalam peroleh segala informasi terkait pendidikan, (3) selalu menanyakan kemungkinan adanya kesulitan belajar atau masalah lain dan (4) senantiasa memantau perkembangan akademik mahasiswa.

Pendidikan Tinggi merupakan industri jasa. Hal ini menunjukkan bahwa pengukuran tingkat kepuasan mahasiswa merupakan elemen penting dalam menyediakan pelayanan yang baik, lebih efisien dan efektif. Sangat disarankan agar dosen pembimbing akademik di lingkungan Poltekkes Palembang segera memperbaiki atribut yang dinilai mahasiwa kurang memuaskan. Penelitian mendatang dapat dilakukan dengan mengkaji kualitas pelayanan yang berorientasi pada pelanggan (dalam hal ini mahasiswa), sebagai salah satu cara menciptakan kepuasan pelanggan dan loyalitas pelanggan.

\section{Acknowledgement}

Terima kepada semua pihak yang sudah bekerja keras membantu terlaksananya penelitian ini. Terutama kepada Poltekes Kemenkes Palembang.

\section{Daftar Pustaka}

Astuti, T.D. 2009. Analisis Perbedaan Harapan Kualitas Jasa Pendidikan (Studi Empiris dapa Program Studi Akutansi di Perguruan Tinggi di Yogyakarta). Fenomena, Vol 7 No. 1.

Bimbingan Akademik Mahasiswa Poltekkes Kemenkes Palembang Tahun 2015/2016.

F. Tjiptono, dan G. Chandra. (2005), Service, Quality \& Satisfaction, Yogyakarta: Penerbit Andi .

Ginting. (2003). Hubungan persepsi terhadap program pengembangan karir dengan kompetisi kerja. Universitas Sumatera Utara: Fakultas Kedokteran Program Studi Psikologi.

Ilyas. 2011. Peran Ideal Dosen Pembimbing Akademik dan Prestasi Belajar Mahasiswa. Educare: Jurnal Pendidikan dan Budaya. http://educare.efkipunla.net.

Mulyadi. 2013. Peran dan Fungsi Dosen Penasihan Akademik. Jurnal Proislamika.

Peraturan Pemerintah No. 4 tahun 2014 tentang penyelenggaraan pendidikan tinggi dan perguruan pendidikan tinggi.

Prayitno dan Amti, E. (2008). Dasar-Dasar Bimbingan dan Konseling. Jakarta: Rineka Cipta.

Silitonga. 2008. Peranan Dosen Wali Bagi Mahasiswa. Diperoleh di http://educare.e-fkipunla.net.

Simorangkir, M \& Sinaga, A. 2008. Peningkatan Prestasi Akademik Mahasiswa Berprestasi Rendah Melalui Layanan Bimbingan Akademik Berorientasi Pengungkapan Masalah Belajar. Indonesian Scientific Journal.

Sopiatin, P. (2010). Manajemen Belajar Berbasis Kepuasan Siswa. Bogor: Ghalia Indonesia.

Sugiyono. (2010). Statistik Untuk Kesehatan. Cetakan keempat. Bandung: CV Alfabeta.

Sulaiman. 2008. Dosen wali. Diperoleh di www.kesling.web.id.

Supranto. (2006). Pengukuran Tingkat Kepuasan Pelanggan. Jakarta: Rineka Cipta. 
P- ISSN: 2527-5798, E-ISSN: 2580-7633

Jurnal Keperawatan Suaka Insan (JKSI) Vol. 5, No. 2, Desember 2020

Slameto. (2003). Belajar dan Faktor-faktor Yang Mempengaruhinya. Jakarta: Rineka Cipta.

Undang-undang Republik Indonesia No. 14 Tahun 2005. Jakarta: Direktorat Jendral Dikti. 